\title{
Effect of hydroxyapatite nanoparticles on enamel remineralization and estimation of fissure sealant bond strength to remineralized tooth surfaces: an in vitro study
}

Mahtab Memarpour ${ }^{1}$, Fereshteh Shafiei ${ }^{2}$, Azade Rafiee ${ }^{1 *} \mathbb{D}$, Mina Soltani ${ }^{1}$ and Mohammad Hossein Dashti ${ }^{3}$

\begin{abstract}
Background: The management of noncavitated caries lesions before sealant therapy is a clinical challenge when the tooth needs sealant application. Sealing noncavitated carious lesions in pits and fissures may lead to failure of the fissure sealant (FS) due to incomplete sealing. Therefore the use of remineralizing agents such as nanoparticles has been suggested. This study investigated the ability of hydroxyapatite nanoparticles (nano-HA) to remineralize enamel, and their effect on sealant microleakage and shear bond strength (SBS).
\end{abstract}

Methods: A total of 192 third molars were demineralized and pretreated with two concentrations of nano-HA with and without sodium hexametaphosphate (SHMP), followed by phosphoric acid etching and resin FS application. The study groups were 1) etching + FS, 2) etching + nano-HA 0.15\% + FS, 3) etching + nano-HA 0.03\% + FS, 4) etching + mixture of nano-HA $0.15 \%$ and SHMP $0.05 \%+F S$, 5) etching + mixture of nano-HA $0.03 \%+$ SHMP 0. $01 \%+F S$. The laboratory tests included microleakage in 50 teeth, scanning electron microscopy (SEM) evaluation in 10 samples, and SBS in 100 samples. Enamel remineralization changes were evaluated in 32 teeth with energydispersive $X$-ray spectroscopy (EDS) and field emission scanning electron microscope (FESEM).

Results: Nano-HA enhanced the SBS to remineralized enamel in a large percentage of nanoparticles. Mean SBS in group 2 was significantly greater than in groups 1,3 and 4 (all $P<0.05$ ). SBS was related to nano-HA concentration: nano-HA $0.15 \%$ yielded greater SBS $(16.8 \pm 2.7)$ than the $0.03 \%$ concentration $(14.2 \pm 2.1)$. However, its effect on microleakage was not significant. Nano-HA with or without SHMP led to enhanced enamel remineralization; however, the Calcium (Ca)/Phosphate (P) weight percent values did not differ significantly between the groups $(P>0.05)$. SEM images showed that SHMP did not affect sealant penetration into the deeper parts of fissures. FESEM images showed that adding SHMP led to increased nanoparticle dispersal on the tooth surface and less cluster formation.

Conclusions: The ultraconservative approach (combining nano-HA 0.15\% and SHMP) and FS may be considered a minimal intervention in dentistry to seal demineralized enamel pits and fissures.

Keywords: Nano-hydroxyapatite, Pit and fissure sealant, Energy-dispersive X-ray spectroscopy, Remineralization

\footnotetext{
* Correspondence: arafiee@sums.ac.ir

${ }^{1}$ Oral and Dental Disease Research Center, Department of Pediatric Dentistry,

School of Dentistry, Shiraz University of Medical Sciences, Shiraz, Iran

Full list of author information is available at the end of the article
}

(c) The Author(s). 2019 Open Access This article is distributed under the terms of the Creative Commons Attribution 4.0 International License (http://creativecommons.org/licenses/by/4.0/), which permits unrestricted use, distribution, and reproduction in any medium, provided you give appropriate credit to the original author(s) and the source, provide a link to the Creative Commons license, and indicate if changes were made. The Creative Commons Public Domain Dedication waiver (http://creativecommons.org/publicdomain/zero/1.0/) applies to the data made available in this article, unless otherwise stated. 


\section{Background}

Pit and fissure sealing is an accepted method to prevent dental caries or arrest the progression of noncavitated carious lesions in the deep parts of occlusal surfaces. The number of bacteria and their production are reduced after pits and fissures are sealed [1]. However, some studies have recommended using a pit and fissure sealant on teeth with noncavitated lesions [2, 3]. In some cases, practitioners may be uncertain about sealing noncavitated carious lesions or incipient caries such as lesions in the deepest parts of pits and fissures. In addition, some dentists have concerns about applying the sealant on decalcified enamel in the deep parts of occlusal grooves or lateral walls of fissures, which are not detectable by visual examination $[4,5]$. Several methods are available for enamel pretreatment prior to sealant therapy, e.g. preparation with burrs, air abrasion or laser $[6,7]$. Some researchers have reported the use of the resin infiltration technique as a microinvasive approach to preserve demineralized enamel. A low-viscous resin infiltrant combined with a flowable composite resin has been used to seal the porous occlusal subsurface in initial caries lesions. This technique increased marginal adaption and internal integrity compared to the use of a conventional flowable composite as a fissure sealant [8].

Other methods use the benefits of remineralizing agents such as pit and fissure sealants containing fluoride, amorphous calcium phosphate or nanoparticles [2, 9-16]. With the introduction of nanotechnology, some researchers have tested the use of nanoparticles in restorative and preventive dentistry [17-19]. One type of nanoparticle used in dentistry is nanohydroxyapatite (nano-HA). Nano-HA was considered promising because of its similarity to the bone and mineral structure of teeth, biocompatibility, and bioactivity $[19,20]$. The particles are "similar in morphology and crystal structure to dental apatite" [21]. The remineralization characteristics of nano-HA particles have been reported in studies in which nanoparticles were added to a glass ionomer or other restorative materials [20,22]. Toothpastes containing nano-HA showed greater remineralization effects in dentin compared to amine fluoride toothpastes [23].

To improve nano-HA infiltration and deagglomerate nano-HA particles, the addition of the deflocculant agent sodium hexametaphosphate (SHMP) to nano-HA has been recommended [24]. This results in more efficient hydroxyapatite crystal remineralization by providing a smaller particle size. Sodium hexametaphosphate is widely used as a food additive (E number E452i), water softener, and dispersing agent to break down clay and other soil types [25]. In the present study the effects of nano-HA with and without SHMP were compared.

Some studies have investigated commercial fissure sealants with nanoparticles added to sealant materials.
These studies focused on the mechanical and chemical properties of the sealants as well as their antibacterial and remineralization characteristics [13-16]. However, no data are available on the use of nano-HA with pit and fissure sealants in demineralized enamel. The aim of the present study was to investigate the efficacy of nano-HA applied prior to the pit and fissure sealant to remineralize artificial enamel caries lesions. Our hypothesis (H0) was that two concentrations of nano-HA would be similar to conventional fissure sealant in their ability to infiltrate demineralized enamel without influencing the sealant's sealing ability or bond strength of the sealant to tooth surface. The null hypothesis was tested against an alternative hypothesis (HA) that differences would be found. We compared microleakage and shear bond strength (SBS) after treatment with nano-HA. In addition, we studied the changes in enamel mineral composition and nano-HA particle microstructure with energy dispersive X-ray spectroscopy (EDS) and field emission scanning electron microscopy (FESEM). Scanning electron microscopy (SEM) was used to observe the sealant-enamel interface.

\section{Methods}

The research protocol was approved by the Human Ethics Review Committee of the School of Dentistry, Shiraz University of Medical Sciences. A total of 192 sound extracted third molars were cleaned and disinfected by immersion in $0.1 \%$ chloramine $\mathrm{T}$ solution for 4 weeks. The aim of the study was explained to patients who decided to have their third molar extracted, and their informed consent in writing was obtained. The teeth were observed under a stereomicroscope (Motic K, Wetzlar, Germany) at 20x to rule out those with defects, cracks or caries.

\section{Early caries lesions}

Briefly, for microleakage and SEM assessment, each tooth was randomly selected and demineralized by immersion in $15 \mathrm{~mL}$ demineralization solution at $37^{\circ} \mathrm{C}$ for $96 \mathrm{~h}$. For SBS, EDS and FESEM studies, the specimens were demineralized followed by polishing and sonication of the buccal and lingual enamel surfaces. The demineralization solution contained $6 \mu \mathrm{M}$ methyl hydroxydiphosphonate, $50 \mathrm{mM}$ lactic acid solution, $3 \mathrm{mM}$ calcium chloride dihydrate and $3 \mathrm{mM}$ potassium dihydrogen phosphate, and the final $\mathrm{pH}$ was adjusted to 4.5 [26]. The solution was replaced with freshly made solution after $48 \mathrm{~h}$. After $96 \mathrm{~h}$, each sample was washed with deionized water for $20 \mathrm{~s}$, air dried and subjected to different conditions as detailed below.

\section{Preparation of the nano-HA solution}

Before starting tooth treatments, nano-HA particle size (nano-HA, Merck, nGimat, Darmstadt, Germany) was measured with a nanoparticle size analyzer (Horiba Ltd., 


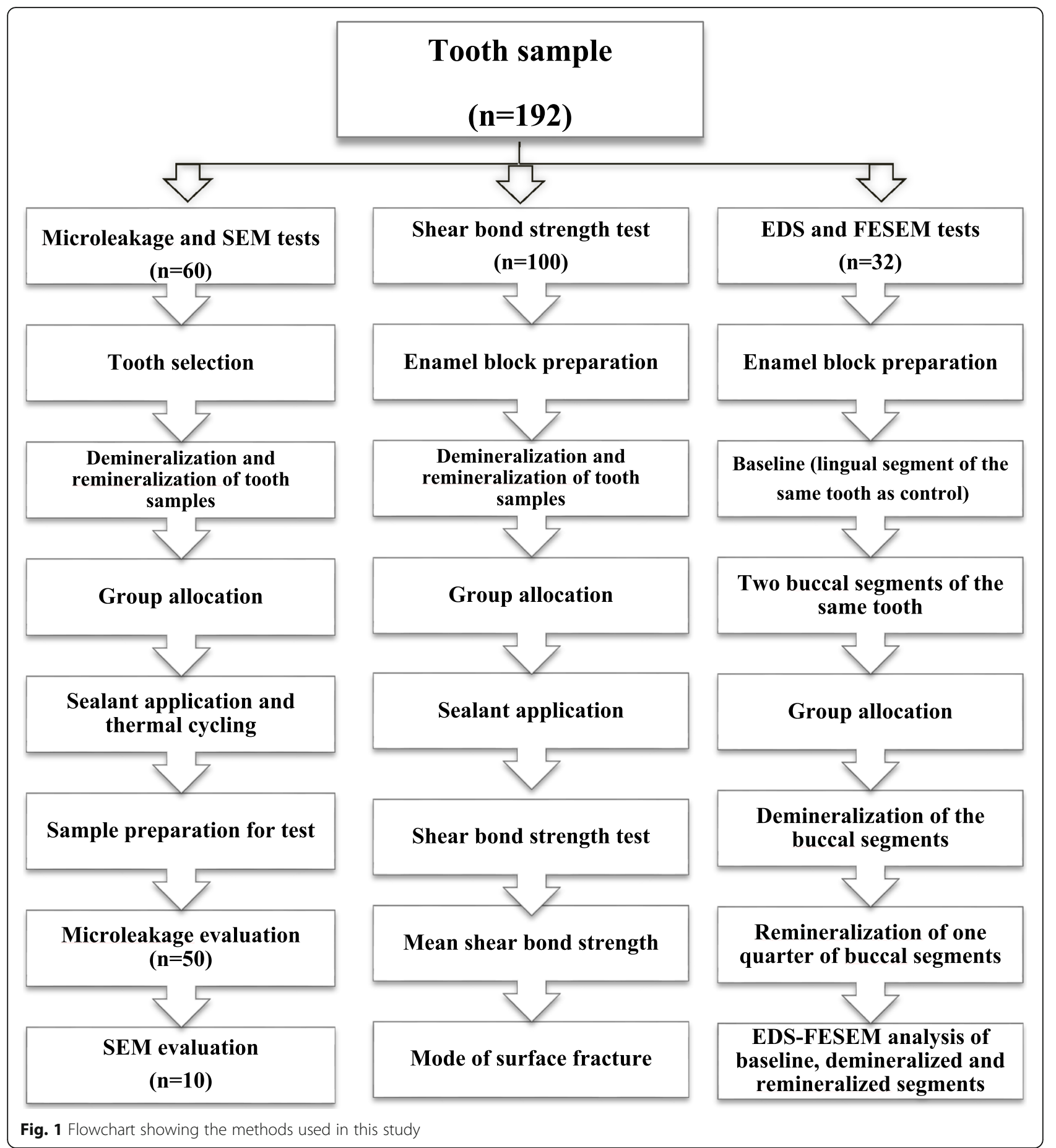

Kyoto, Japan). The average diameter of the particles was recorded as $10.67 \mathrm{~nm}$. Then two types of nano-HA were prepared, one with and one without SHMP (Merck, nGimat, Darmstadt, Germany).

The solution contained distilled water and $\geq 99.5 \%$ acetone (Acetone, Merck, nGimat, Darmstadt, Germany) as a solvent at a 1:1 ratio. The nano-HA and SHMP powder was measured and mixed at a 3:1 ratio and added to the solution. The prepared solutions contained nano-HA $0.15 \%$ or $0.03 \%(\mathrm{w} / \mathrm{v})$ and SHMP at $0.05 \%$ or $0.01 \%(\mathrm{w} / \mathrm{v})$. The amounts of powder and solvent needed to produce suitable concentrations of nano-HA and SHMP for testing were determined according to previous research [24] and a pilot study carried out in our laboratory. 
Table 1 Means and standard deviations of the proportion of microleakage in all groups $(n=10)$

\begin{tabular}{llll}
\hline Group & $\begin{array}{l}\text { Median } \\
\text { (mean } \pm \text { SD })\end{array}$ & Mean rank & p-value \\
\hline 1. Etch + FS & $0.0(0.09 \pm 0.17)$ & 52.2 & 0.939 \\
2. Etch + 0.15\% nano-HA + FS & $0.0(0.09 \pm 0.18)$ & 52.3 & \\
3. Etch + 0.03\% nano-HA + FS & $0.0(0.08 \pm 0.23)$ & 49.7 & \\
$\begin{array}{l}\text { 4. Etch + nano-HA 0.15\%+ } \\
\text { SHMP 0.05\% + FS }\end{array}$ & $0.0(0.08 \pm 0.23)$ & 50.9 & \\
5. Etch + nano-HA 0.03\%+ & $0.0(0.05 \pm 0.13)$ & 47.3 & \\
SHMP 0.01\%+FS & & & \\
\hline
\end{tabular}

Abbreviations: nano-HA nanohydroxyapatite, FS pit and fissure sealant, SHMP sodium hexametaphosphate

\section{Experimental groups}

After demineralization, the enamel was pretreated as follows and fissure sealant was applied:

Group 1 (control): The enamel was etched with phosphoric acid 35\% (3 M, ESPE, St. Paul, MN, USA) for 20 $\mathrm{s}$, rinsed and dried under a weak air stream. Then an unfilled fissure sealant (FS) (Clinpro, $3 \mathrm{M}$ ESPE, St. Paul, Minn, USA) was applied and cured with a halogen light curing unit (Coltolux, Coltene, Whaledent, Altstaetten, Switzerland) at a power density of $550 \mathrm{~mW} / \mathrm{cm}^{2}$ for $40 \mathrm{~s}$.

Group 2 (nano-HA 0.15\%): After the enamel was etched as described above for group 1, each sample was immersed in $5 \mathrm{~mL}$ of a solution that contained $0.15 \%$ nano-HA in a closed glass vial with continuous slow speed rotation ( $4 \mathrm{rmp}$ ) for $5 \mathrm{~min}$ to ensure that the nanoparticles remained in suspension and to avoid precipitation [24]. Then each tooth was dried under an air stream and the sealant was applied.

Group 3 (nano-HA 0.03\%): The procedures were similar to group 2, except that the solution contained nano-HA at $0.03 \%$ concentration.

Group 4 (nano-HA 0.15\% + SHMP 0.05\%): The solution powder contained nano-HA $0.15 \%$ and SHMP 0.05\%, which were mixed together before the solvent was added. The other procedures were similar to groups 2 and 3 .

Table 2 Means and standard deviations of shear bond strength (unit MPa; $n=20$ ) after different enamel pretreatments

\begin{tabular}{lll}
\hline Group & Mean \pm SD & Duncan's test $^{a}$ \\
\hline 1. Etch + FS & $14.6 \pm 2.5$ & A \\
2. Etch + 0.15\% nano-HA + FS & $16.8 \pm 2.7$ & B \\
3. Etch + 0.03\% nano-HA + FS & $14.2 \pm 2.1$ & A \\
4. Etch + nano-HA 0.15\% + SHMP & $14.0 \pm 2.2$ & A \\
$\begin{array}{l}\text { 0.05\% + FS } \\
\text { 5. Etch + nano-HA 0.03\% + SHMP }\end{array}$ & $15.1 \pm 2.5$ & AB \\
$\begin{array}{l}\text { 0.01\% + FS } \\
\text { p-value }\end{array}$ & 0.010 & - \\
\hline
\end{tabular}

${ }^{a}$ Mean values with different capital letters were significantly different Abbreviations: nano-HA nanohydroxyapatite, FS pit and fissure sealant, SHMP sodium hexametaphosphate
Group 5 (nano-HA 0.03\% + SHMP 0.01\%): The procedures were similar to group 4, except that the solution contained nano-HA at $0.03 \%$ and SHMP at $0.01 \%$.

\section{Microleakage assessment}

A total of 60 selected demineralized teeth were randomly divided into 5 groups of 12 teeth each and pretreated as explained above. After the sealant was applied and cured, the teeth were aged in a thermocycling bath at temperatures between $5{ }^{\circ} \mathrm{C}$ and $55^{\circ} \mathrm{C}$ for 1000 cycles with a dwell time of $30 \mathrm{~s}$ and a $15 \mathrm{~s}$ transit time between baths. Two samples in each group were randomly selected for SEM evaluation.

Next the root apices were sealed and each tooth surface was covered with two layers of nail polish, leaving a 1-mm margin around the sealant. Then the samples were immersed in $0.5 \%$ basic fuchsin dye (Merck, Darmstadt, Germany) solution for $24 \mathrm{~h}$, rinsed and sectioned buccolingually across the sealant area with a diamond saw (Mecatome, Presi, Eybens, France) to obtain two halves of the sealant. Two dentists who were trained prior to the study observed the sectioned teeth under a calibrated digital microscope (Dino Lite, Taipei, Taiwan) at $50 \times$ magnification. The proportion of microleakage was calculated by dividing the total distance of dye penetration (in $\mathrm{mm}$ ) by the total length of the enamel sealant interface (in $\mathrm{mm}$ ) [27].

\section{Scanning electron microscopy evaluation}

After the sealant was applied on the occlusal surface and the teeth were aged, two samples from each group were randomly selected to evaluate resin infiltration and the interface area. The teeth were sectioned transversally to the sealant-tooth interface and polished with 400, 600, 1000 and 2000 grit silicon carbide paper (SCi) with water cooling. Then the tooth surface was treated with $37 \%$ phosphoric acid for $10 \mathrm{~s}$, rinsed for $30 \mathrm{~s}$, and immersed in $5 \% \mathrm{NaOCl}$ for $2 \mathrm{~min}$. After rinsing, the teeth were dehydrated with ethanols. Next the samples were sputter-coated with gold in a vacuum evaporator, and the interfaces were examined with SEM (VEGA, Tescan, Brno, Czech Republic) at $1500 \times$ magnification.

\section{Shear bond strength test}

The root of 100 teeth was sectioned perpendicular to and $2 \mathrm{~mm}$ below the cementoenamel junction with a diamond saw. Then the enamel specimens were prepared in blocks so that the crown was embedded in acrylic resin while the buccal surface remained exposed. To obtain a flat surface the exposed enamel was polished with 600-1000 grit waterproof SCi. Each sample was demineralized, and the enamel was sonicated for $10 \mathrm{~min}$ to remove any debris due to surface polishing [24]. Then the teeth were randomly divided into 5 groups and 


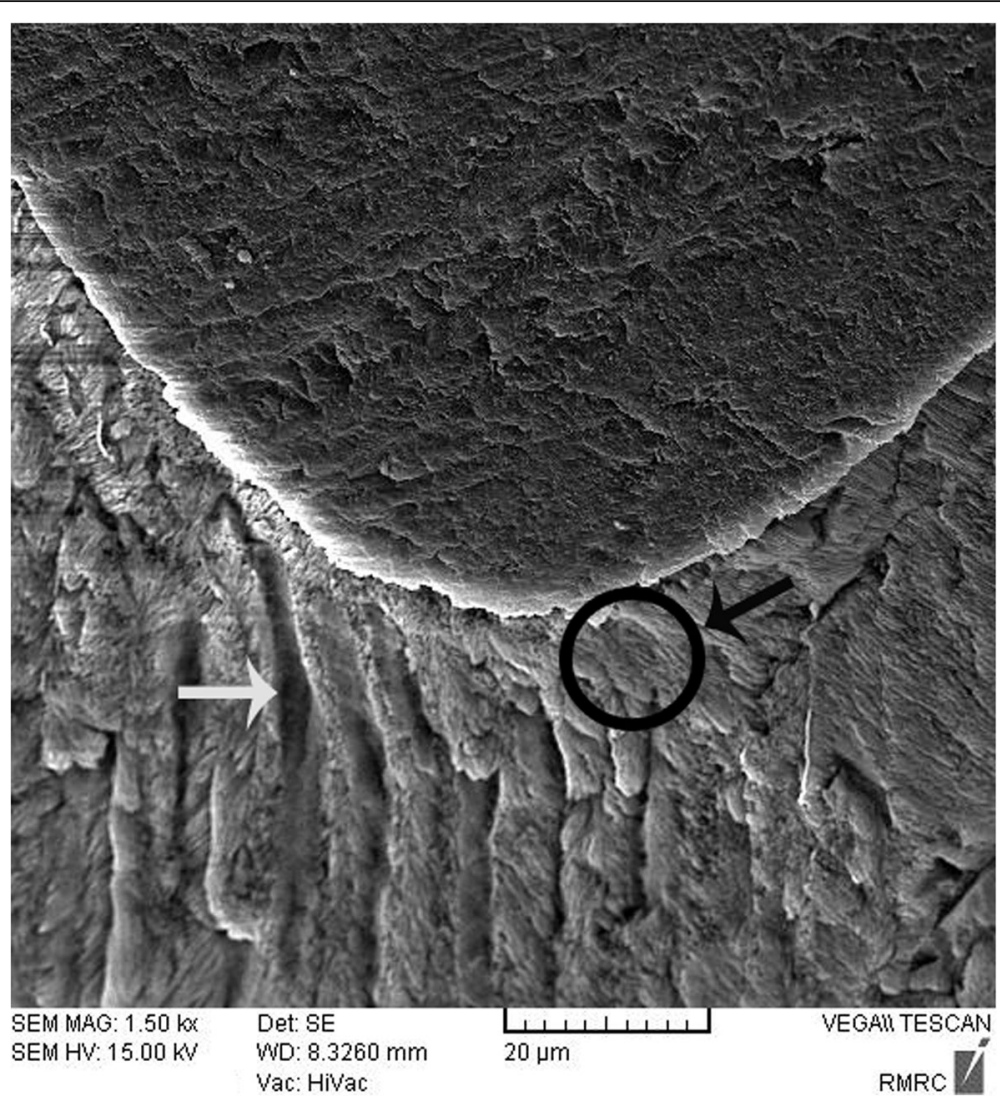

Fig. 2 SEM images of demineralized etched enamel and resin sealant adaptation on the interface (group 1). The white arrow shows the noninfiltrated area. The black arrow and circle show the infiltrated area. Abbreviations: SEM, scanning electron microscopy

pretreatment was applied to each sample as described above. Next a rubber cylindrical mold $3 \mathrm{~mm}$ in internal diameter and $3 \mathrm{~mm}$ in height was placed on the treated enamel and filled with fissure sealant material, which was then cured. Then the teeth were stored in humid conditions at $37^{\circ} \mathrm{C}$ for $24 \mathrm{~h}$, and SBS tests were done with a universal testing machine (Zwick-Roell, Zwic, Ulm, Germany). The load speed applied in a direction parallel to the bonded interface was $1 \mathrm{~mm} / \mathrm{min}$ until failure occurred, and load failure was recorded in megapascals (MPa). Failure mode of the fractures was evaluated by two previously trained observers under blind conditions with a digital microscope (Dino Lite) at $25 \times$ magnification. The types of bond failure were recorded as follows: 1) adhesive fracture at the sealant-enamel interface, 2) cohesive fracture in the substrate (enamel or sealant), 3) mixed fracture when both adhesive and cohesive fractures occurred.

\section{Energy dispersive X-ray spectroscopy and field emission scanning electron microscopy}

A total of 32 teeth were selected and randomly divided into 4 groups of 8 specimens. Each tooth was sectioned transversally in the mesiodistal direction to obtain baseline sound enamel (the enamel surface of the lingually sectioned portion). Enamel blocks were prepared as described above. Then the buccal half of the sectioned teeth was cut in the buccolingual direction to obtain two quarters of the tooth. All parts of each tooth were sonicated for $10 \mathrm{~min}$. The two buccal quarters were demineralized as described above. One quarter of each sample was pretreated (remineralized) as explained above, and the other quarter was used to study demineralization. Next the mineral content of each sample was measured by EDS at baseline (in sound enamel), after demineralization, and after immersion in nano-HA solution (remineralization). The sound sectioned part of each specimen was used as a reference for comparisons with the demineralized and remineralized enamel specimens. In other words all comparisons were done in all 32 tooth specimens.

Before EDS analysis, the teeth were carbon coated. The scanning parameter settings and tooth position were held constant to standardize the analytical method and obtain comparable results. The spot size was kept at $100 \mathrm{~nm}$ for EDS and 2-3 nm for FESEM. The surface area assessed in each FESEM scan was $1.38 \mu \mathrm{m}$ (at $75000 \times$ ) at $15 \mathrm{kV}$. Scan duration was $45 \mathrm{~s}$. In addition, EDS associated with high-resolution FESEM (MIRA3, Tescan, Brno, Czech 
Republic) was used for samples in groups 2 to 5 to observe nanoparticles in each sample (Fig. 1).

\section{Statistical analysis}

All data are presented as means \pm standard deviations (SD), and were obtained with SPSS version 22.0 (IBM SPSS) software. Microleakage and SBS comparisons were done with the Kruskal-Wallis, one-way analysis of variance (ANOVA) and Duncan's post hoc tests. Repeated measures ANOVA, the Sidak and Tukey post hoc tests were used to compare the effect of different nano-HA compositions and conditions. $P$ values $<0.05$ were considered statistically significant.

\section{Results}

\section{Microleakage and shear bond strength}

Table 1 shows the mean $( \pm S D)$ of the proportion of microleakage values in each group. There were no significant differences between the groups $(P=0.939)$. However, the differences between groups in mean $( \pm \mathrm{SD})$ SBS were significant (Table 2). Mean SBS in group 2 was significantly greater than in groups 1,3 and 4 (all $P<$ $0.05)$. There were no significant differences in SBS between group 5 and the other groups. The results of failure mode tests showed that mixed failure was the most frequent mode in all groups.

\section{Sealant penetration}

Sealant penetration was investigated with SEM in the deepest part of the pit and fissures in group 1. The prism-like appearance well was defined due to the demineralization process and effect of etching. The spaces were filled with resin sealant (Fig. 2). Applying nano-HA $0.15 \%$ created a layer that covered the surface and penetrated into parts of the etched enamel (Fig. 3). The use of nano-HA $0.03 \%$ led to resin infiltration in parts of the fissures, although some parts showed no penetration (Fig. 4). Applying SHMP in group 4 (Fig. 5) and group 5 (Fig. 6) led to increased dispersal of the nanoparticles over a larger area, with no increase in the depth of infiltration in the fissures.

\section{Mineral content}

Mineral contents in each sample at all three steps were measured by EDS. There was no significant interaction between compositions and conditions $(P=0.794)$. In other words, the effect of different conditions on the Calcium $(\mathrm{Ca}) /$ Phosphate $(\mathrm{P})$ ratio did not depend on the type of

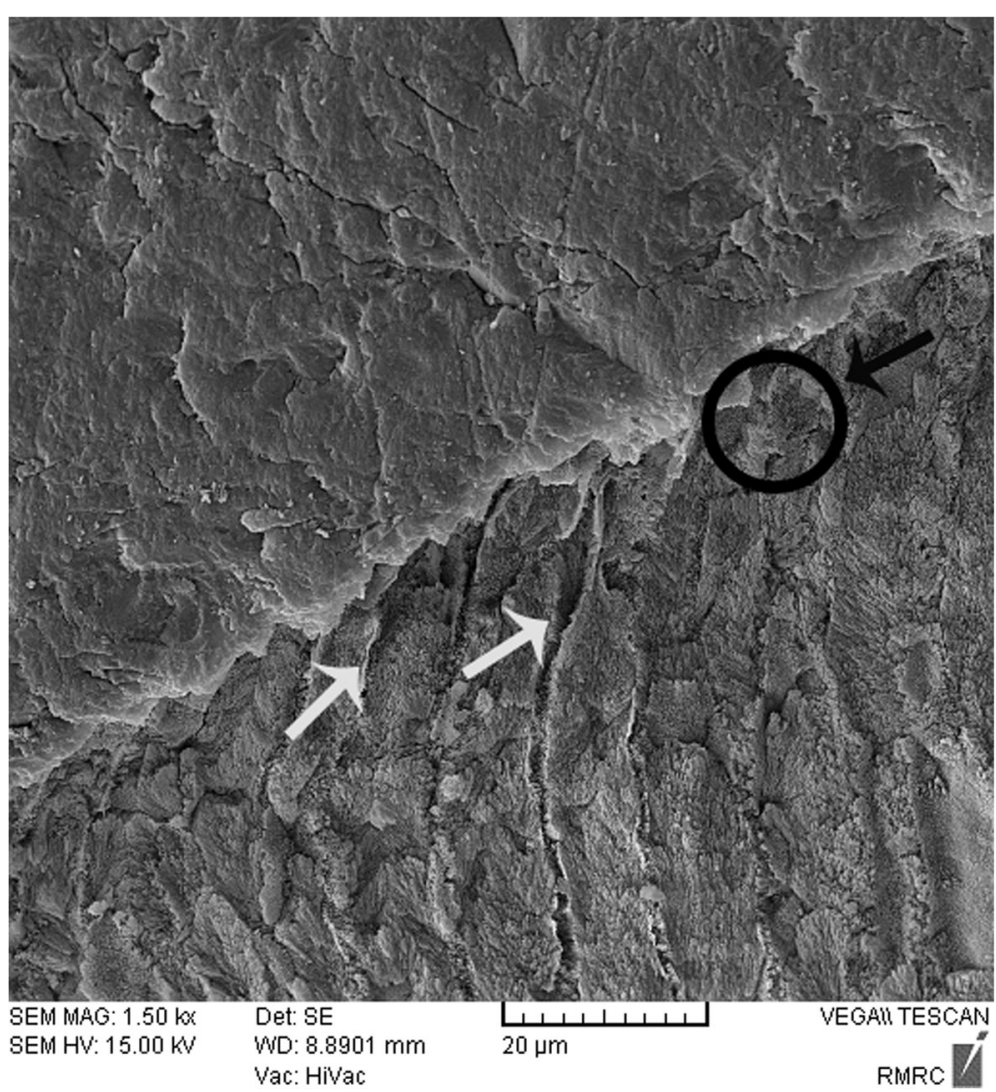

Fig. 3 SEM image of nano-HA (0.15\%) deposition on the pretreated enamel surface (group 2). The white arrow shows the non-infiltrated area. The black arrow and circle show the infiltrated area. Abbreviations: nano-HA, nanohydroxyapatite 


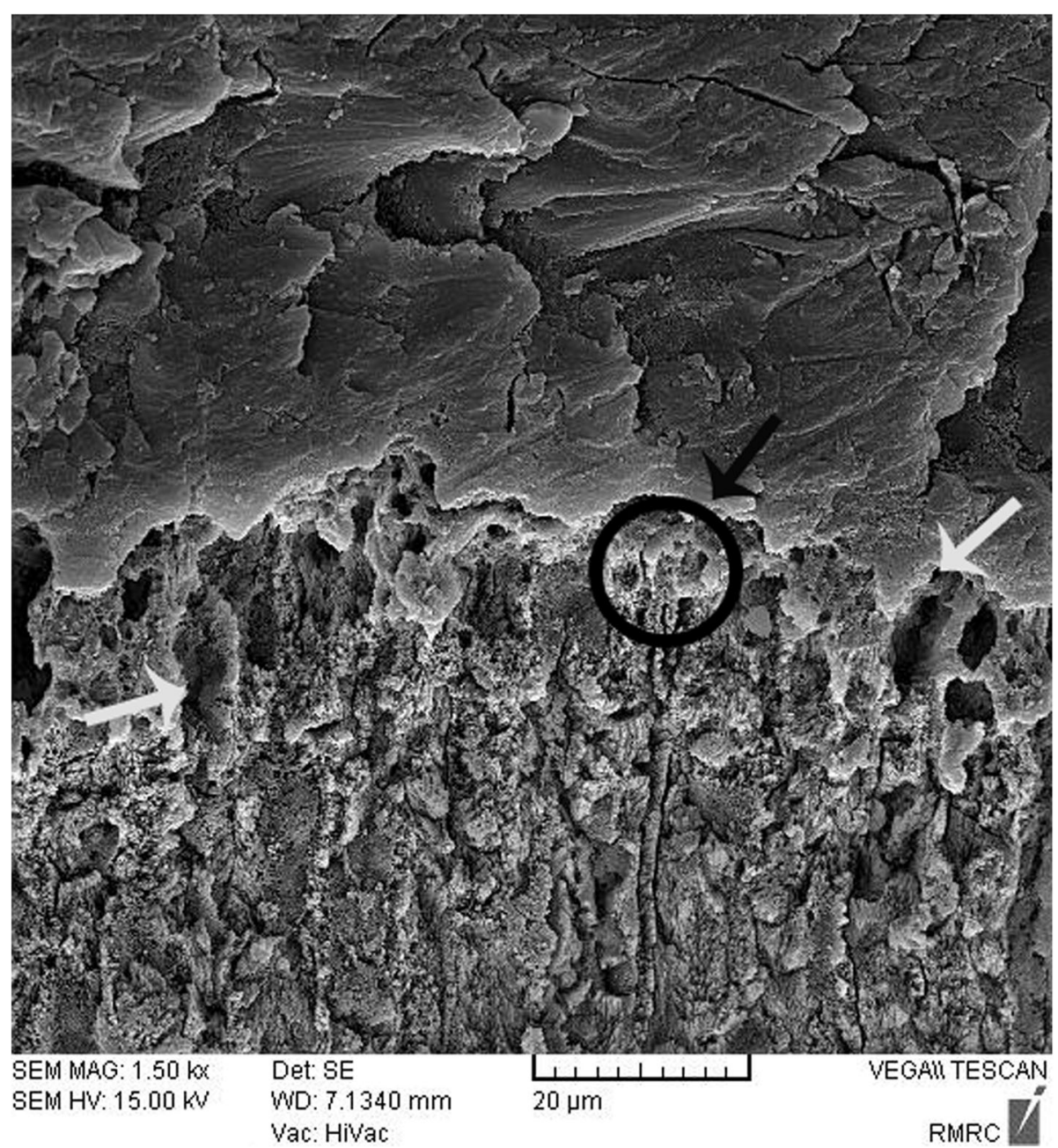

Fig. 4 SEM image of nano-HA (0.03\%) deposition on the tooth surface, showing absence of nanoparticle infiltration in some areas (group 3). The white arrow shows the non-infiltrated area. The black arrow and circle show the infiltrated area

composition used (Fig. 7). There were significant differences in $\mathrm{Ca} / \mathrm{P}$ weight percentage $(\mathrm{Wt} \%$ ) ratio between baseline, demineralized and remineralized enamel $(P<0.001)$ (Table 3). The highest ratio was recorded for sound enamel and the lowest for demineralized enamel. There were no significant differences in $\mathrm{Ca} / \mathrm{P} \mathrm{Wt} \%$ ratio between groups 2 , 3,4 and 5 regardless of the conditions $(P=0.582)$.

The standardless EDS value with ZAF correction for matrix effects (EDS-ZAF) was also recorded. There was no significant interaction between compositions and conditions $(P=0.385)$. In other words, the effect of changing $\mathrm{ZAF}$ for $\mathrm{Ca} / \mathrm{P}$ from demineralization to remineralization did not depend on the type of composition used (Fig. 8). The results showed significant differences in ZAF $\mathrm{Ca} / \mathrm{P}$ ratios between all groups $(P<0.001)$ and between groups 2 to $5(P=0.004)$. There were significant differences in ZAF-corrected $\mathrm{Ca} / \mathrm{P}$ ratios between groups 4 and $3(P=0.014)$ and groups 4 and 5
$(P=0.019)$. However, there was no significant difference between groups 4 and $2(P=0.857)$. Also regardless of the group, the ratio in remineralized enamel was significantly higher compared to after demineralization $(P<$ 0.001 ). Table 4 shows the mean $\mathrm{ZAF} \mathrm{Ca} / \mathrm{P}$ ratios in different conditions and groups.

\section{Nanoparticle micromorphology}

Nano-HA particles were spherical in all the interventional groups. The structure was porous, and large numbers of nanoparticles were dispersed on the surface in group 2 (Fig. 9). The FESEM images for group 3 revealed a similar appearance except with fewer nanoparticles and less particle clustering (Fig. 10). Applying SHMP (groups 4 and 5) resulted in nano-HA dispersal over a larger surface area and less clustering (Figs. 11 and 12) compared to the groups without SHMP. 


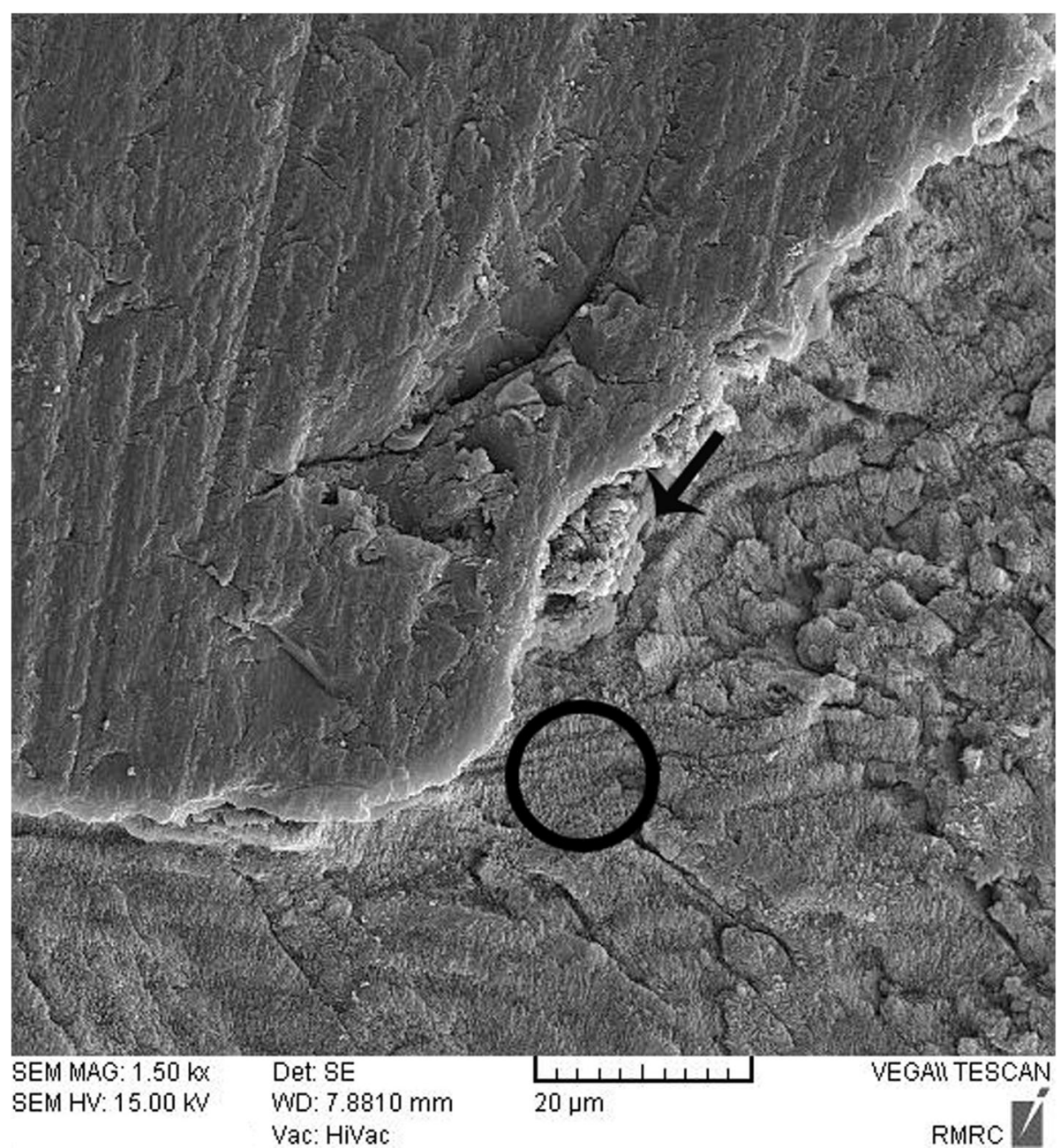

Fig. 5 SEM image of nano-HA dispersal across a larger area in group 4 (nano-HA 0.15\% + SHMP 0.05\%) compared to group 2. The black arrow and circle show the infiltrated area

\section{Discussion}

The present results showed no significant difference between intervention groups and the control group (FS alone), which was in accordance with our null hypothesis. The higher concentration of nano-HA $(0.15 \%)$ led to greater SBS compared to the control group; however, there was no significant difference between the control group and the group with the lower concentration $(0.03 \%)$ of nano-HA. Thus the null hypothesis $(\mathrm{H} 0)$ was partially rejected.

Guidelines have recommended using a pit and fissure sealant on sound intact enamel and noncavitated (incipient caries) lesions $[2,3]$. Some materials, such as nanoparticles, have been found to increase enamel remineralization in sealant therapy [13-16].

Nano-HA $\left[\mathrm{Ca}^{10}\left(\mathrm{PO}_{4}\right)^{6}(\mathrm{OH})^{2}\right]$ is similar in structure to the main mineral component of teeth and bone, and products containing nanoparticles have led to enhanced precipitation of calcium and phosphate ions in the tooth structure $[14,20,28]$. Some studies reported that a suspension containing $10 \%$ nano-HA particles $(10-20 \mathrm{~nm}$ diameter) enhanced remineralization of the superficial layer in initial caries lesions to a depth of $20-40 \mu \mathrm{m}$. However, little remineralization was seen in the body of the lesion $[29,30]$. One earlier study found that nano-HA (20 nm size and dimension up to $100-150$ $\mathrm{mm}$ ) enhanced remineralization in the subsurface of initial lesions, particularly in dentin compared to enamel [23]. In the present study the mean diameter of nano-HA was $10.67 \mathrm{~nm}$.

Factors that influence the success of sealant treatment include marginal adaptation between the tooth and fissure sealant, and bond strength of the materials [9, 27]. In the present study all groups showed some microleakage, which is consistent with previous work that found no sealant materials were able to completely eliminate microleakage between the tooth and sealant [30]. Several factors influence microleakage along the sealant 


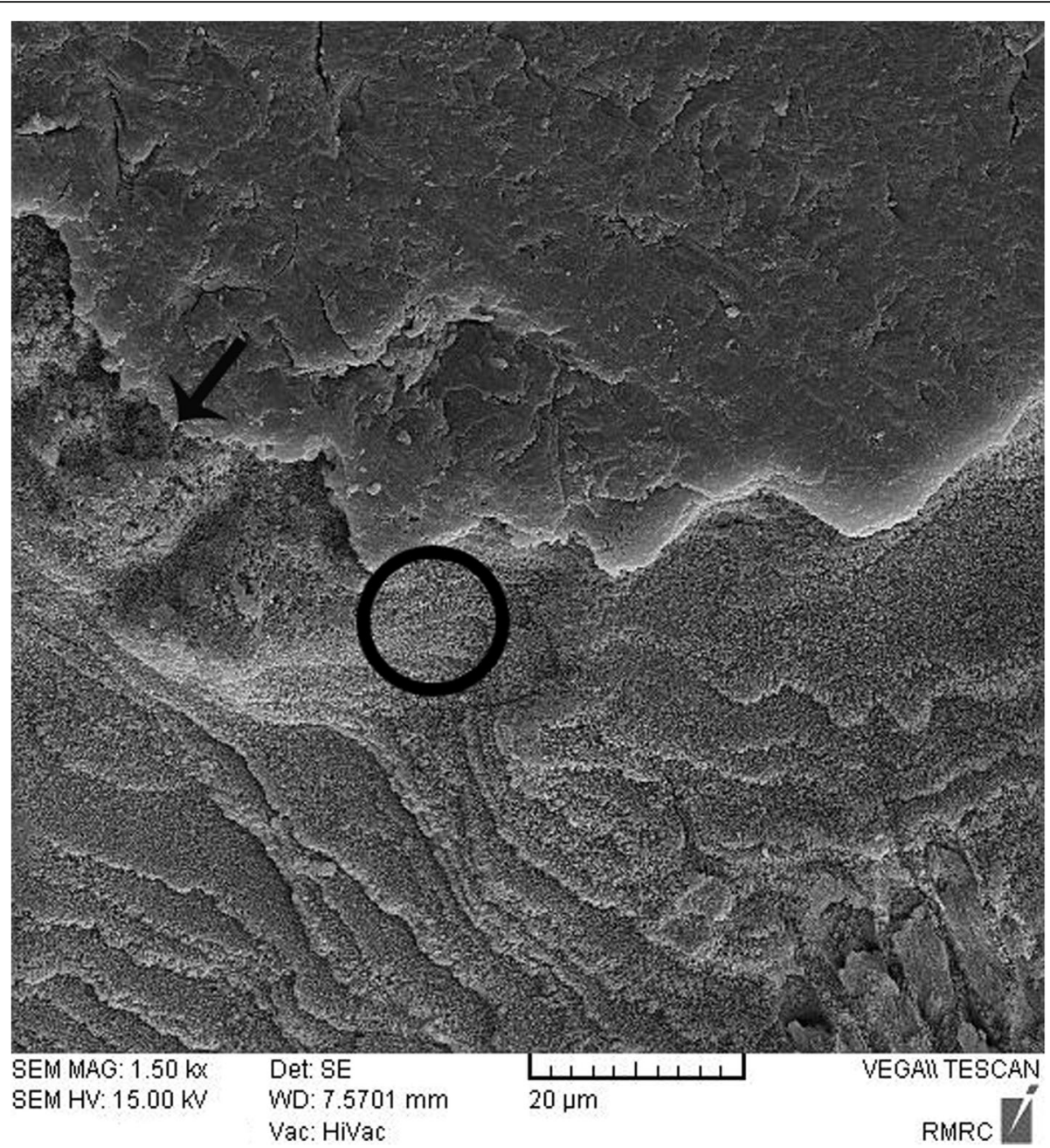

Fig. 6 SEM image of nano-HA dispersal across a larger area in group 5(nano-HA 0.03\%+SHMP 0.01\%) compared to group 4

and enamel surface, e.g. pit and fissure morphology, sealant viscosity and method of FS application, all of which impact sealant infiltration [31]. Other factors include the enamel pretreatment technique [6,7], intensity of light curing [31], and mechanical properties of the sealant materials [31, 32]. Resin polymerization shrinkage as well as thermal dimensional changes in fissure sealants [33] may also lead to microleakage and gap formation. We observed no significant differences between the interventional groups (groups 2 to 5 ) and the control group without nano-HA application. This result is consistent with a previous study in which the use of products containing acetone prior to sealant application led to similar results for sealant adaption compared to conventional acid etching [30]. These findings may be due to the presences of acetone as a solvent in the nano-HA solution. Acetone is a colorless liquid that evaporates rapidly and can be mixed with most organic solvents and with water. Nano- HA solutions containing acetone and water, therefore, may improve resin infiltration into the demineralized enamel [24]. Another explanation for these results may be the lack of a significant effect of nanoparticles on the sealing capacity of the sealant.

In the present study SBS differed significantly between group 2 (nano-HA) and groups 1 (control), 3 and 4 . This may reflect the ability of the hydrophobic resin sealant to enhance surface wettability of the etched enamel as a result of nano-HA properties [16] and the presence of acetone in the solution. Hydroxyapatite "acts as a drug delivery carrier due to superior adsorptive properties", and this may in turn increase bond strength [14]. Another explanation for the increased bond strength may be the creation of a reactive layer between the resin sealant and nano-HA. In group 2 the higher concentration of nanoparticles $(0.15 \%)$ may have contributed to the greater SBS. In agreement with our study, Borges et al. showed that applying casein phosphopeptide-amorphous calcium phosphate (CPP-ACP) products beneath the fissure sealant promoted bond strength between the resin sealant and the enamel [12]. 


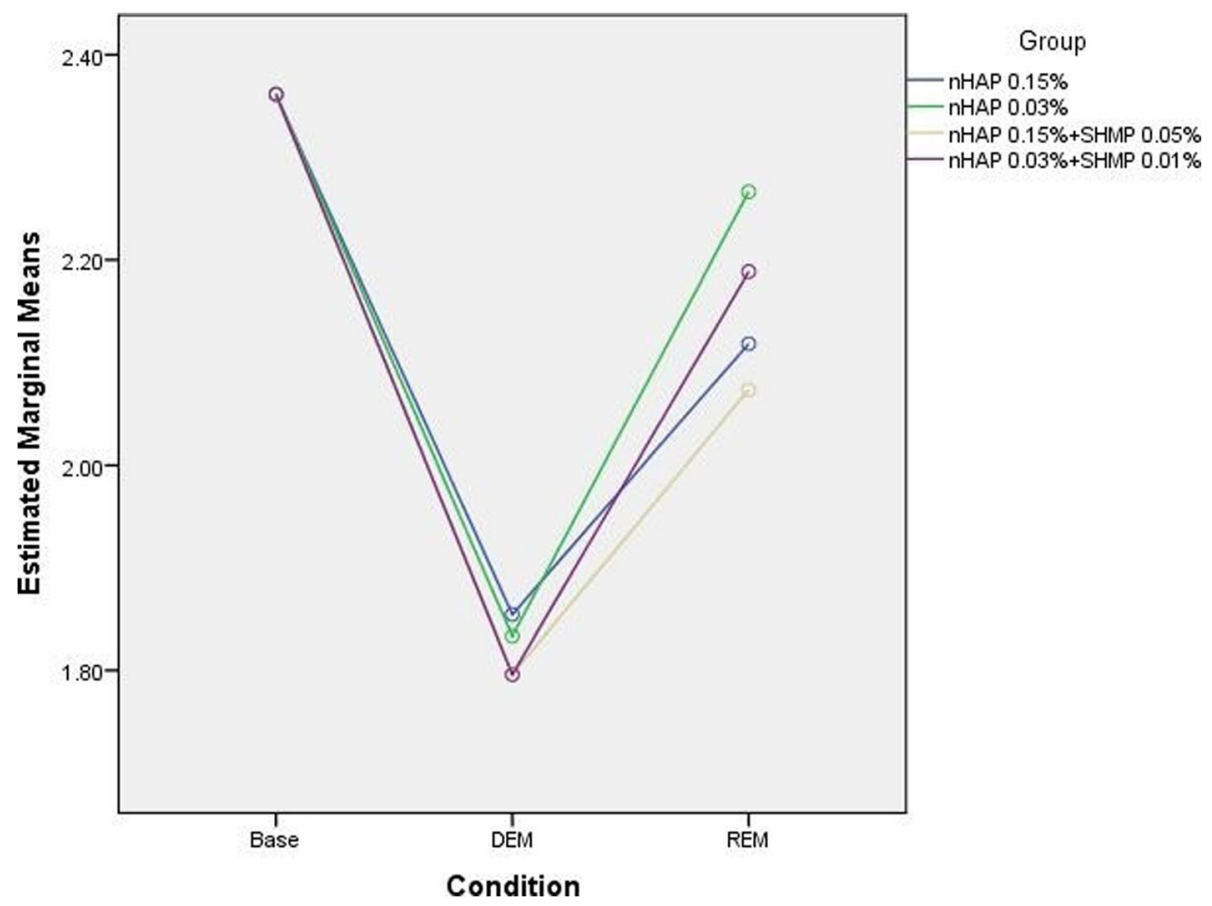

Fig. 7 Mean Ca/P wt\% ratio in experimental groups under different conditions

After enamel demineralization, the loss of minerals such as calcium and phosphorus results in voids or gaps on the tooth surface. The acid etch technique also creates microporosities on the enamel surface. Both processes provide spaces that facilitate resin infiltration and suitable bonding between the resin and tooth. When nano-HA solution was used, the ionic form of $\mathrm{Ca}$ and $\mathrm{P}$ enters the porous enamel and provides seeds for remineralization [25, 28, $34,35]$. SEM images in the present study showed differences between groups in the degree of penetrations of the resin sealant into these spaces.

Energy dispersive X-ray spectroscopy is a chemical elemental microanalysis technique to measure mineral content at the ultrastructural level, and has been used to investigate the remineralization capacity of different materials $[14,17,24]$. In the present study we used FESEM

Table 3 Means and standard deviations of $\mathrm{Ca} / \mathrm{P} \mathrm{Wt} / \%$ ratio in groups 2 to 5

\begin{tabular}{llllll}
\hline & \multicolumn{3}{l}{ Condition } & & \\
\cline { 2 - 4 } Group & Baseline & DEM & REM & Total & $p$-value \\
\hline 2 & $2.4 \pm 0.1$ & $1.8 \pm 0.2$ & $2.1 \pm 0.3$ & $2.1 \pm 0.1$ & 0.582 \\
3 & $2.4 \pm 0.1$ & $1.8 \pm 0.1$ & $2.3 \pm 0.3$ & $2.1 \pm 0.1$ & \\
4 & $2.4 \pm 0.0$ & $1.8 \pm 0.3$ & $2.1 \pm 0.4$ & $2.1 \pm 0.2$ & \\
5 & $2.4 \pm 0.1$ & $1.8 \pm 0.1$ & $2.2 \pm 0.2$ & $2.1 \pm 0.1$ & \\
Total & $2.4 \pm 0.1$ & $1.8 \pm 0.2$ & $2.2 \pm 0.3$ & $p$-value<0.001 & \\
\hline
\end{tabular}

Abbreviations: wt\% weight percentage, DEM Demineralization, REM Remineralization instead of SEM to obtain more detailed structural data of higher quality and resolution [35]. Our analysis of EDS data focused on changes in $\mathrm{Wt} \%$ of $\mathrm{Ca}, \mathrm{P}$ and the $\mathrm{Ca} / \mathrm{P}$ ratio, given that these ions are important indicators of the effect of nano-HA on enamel remineralization. To enhance the accuracy of our EDS analysis, we compared three portions of each tooth sample at each of three steps: baseline (sound enamel, as a reference), after demineralization, and after remineralization. In addition we obtained the ZAF-corrected $\mathrm{Ca} / \mathrm{P}$ ratio to further increase the accuracy of the EDS results.

Our EDS results showed that nano-HA released Ca and $\mathrm{P}$ ions onto the demineralized surface, in accordance with previous studies [18, 24]. The lowest Ca/P $\mathrm{Wt} \%$ ratios were seen (not unexpectedly) in demineralized enamel. There were no significant differences in this ratio between groups - a finding consistent with earlier EDS results for $\mathrm{Ca} / \mathrm{P}$ ratio in a study of nano-HA in demineralized dentin [24]. This may explain, in part, our finding that $\mathrm{Wt} \% \mathrm{Ca} / \mathrm{P}$ did not differ among our experimental groups. Although SHMP and acetone increase solubility of nano-HA and would thus be expected to enhance nanoparticle infiltration [24], SHMP did not increase nanoparticle infiltration in deeper parts of the enamel in the present study.

In the present study the $\mathrm{ZAF}$-corrected $\mathrm{Ca} / \mathrm{P}$ ratio in demineralized enamel was higher than in the interventional groups, as a foreseeable result of the demineralization process. Among the interventional groups, the 


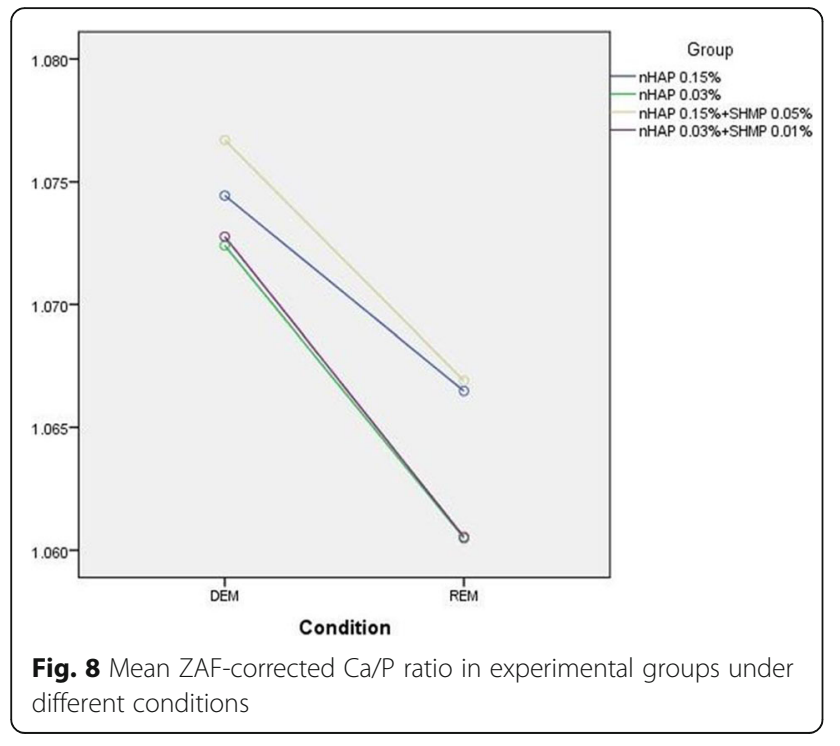

ZAF-corrected ratio in group 4 was significantly higher than in groups 3 and 5 . This may be related to the higher values of $\mathrm{P}$ (i.e. the higher concentration of SHMP) in group $4(0.15 \%$ nano-HA $+0.05 \%$ SHMP $)$. In dentistry, SHMP is used as a deflocculant to limit nanoparticle agglomeration or reduce the size of nano-HA agglomerates to less than $5 \mathrm{~nm}$ [24]. Our SEM observations showed that in groups 4 and 5 (both with SHMP) the nanoparticles were better dispersed on the surface of the sealant-enamel interface than in groups 2 and 3 (without SHMP). In group 1 (control without nano-HA) the sealant penetrated to the deepest parts of pits and fissures. When the higher concentration of nanoparticle was used (group 2), a layer of nano-HA was seen on the treated enamel - a finding consistent with an earlier study with tricalcium phosphate nanoparticles [15]. Group 4 also used nano-HA at $0.15 \%$, together with SHMP, and this combination may have influenced our SBS and SEM results. However, the lack of earlier studies centered on nanoparticles in treated enamel precludes further comparisons with previous findings.

Nanoparticle micromorphology was investigated in FESEM images, which showed that they were spherical as reported in a previous study [18]. In group 2 (with the

Table 4 Means and standard deviations of ZAF-corrected Ca/P ratios in groups 2 to 5

\begin{tabular}{lllll}
\hline & \multicolumn{2}{l}{ Condition } & & \\
\cline { 2 - 3 } Group & DEM & REM & Total & $p$-value \\
\hline 2 & $1.074 \pm 0.006$ & $1.072 \pm 0.007$ & $1.070 \pm 0.005 \mathrm{AB}$ & 0.004 \\
3 & $1.077 \pm 0.006$ & $1.073 \pm 0.007$ & $1.066 \pm 0.004 \mathrm{~A}$ & \\
4 & $1.074 \pm 0.006$ & $1.066 \pm 0.005$ & $1.072 \pm 0.004 \mathrm{~B}$ & \\
5 & $1.060 \pm 0.003$ & $1.067 \pm 0.006$ & $1.067 \pm 0.003 \mathrm{~A}$ & \\
Total & $1.074 \pm 0.006$ & $1.064 \pm 0.005$ & p-value $<0.001$ & \\
\hline
\end{tabular}

Abbreviations: DEM Demineralization, REM Remineralization

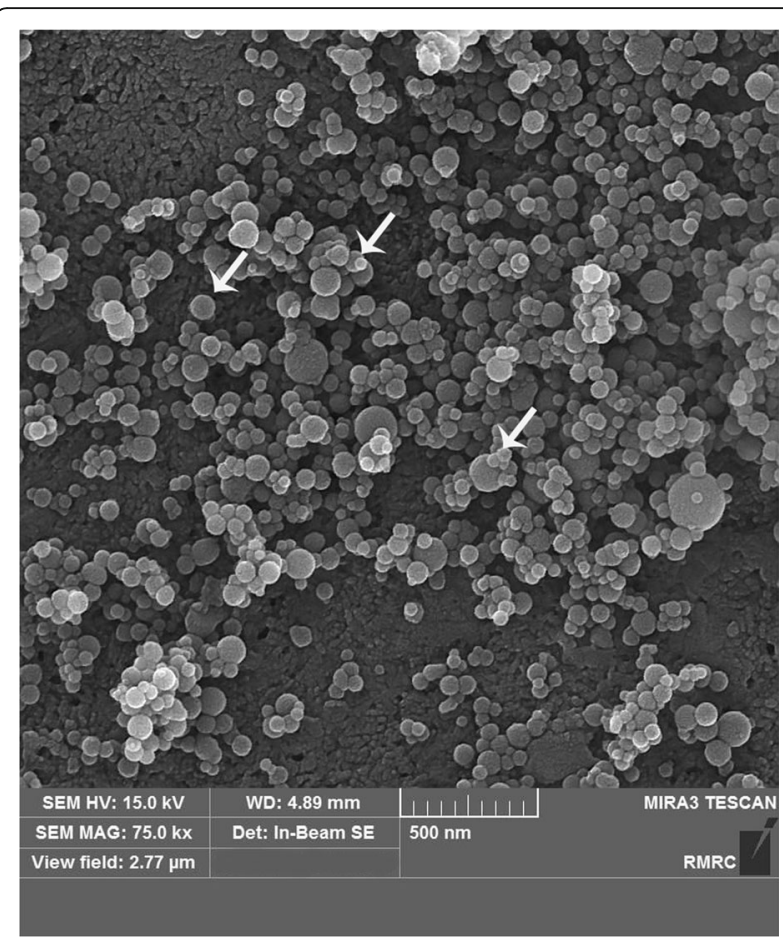

Fig. 9 Field emission scanning electron microscopic (FESEM) image from group 2 showing spherical nanoparticles dispersed on the enamel. The white arrow shows spherical nanoparticles

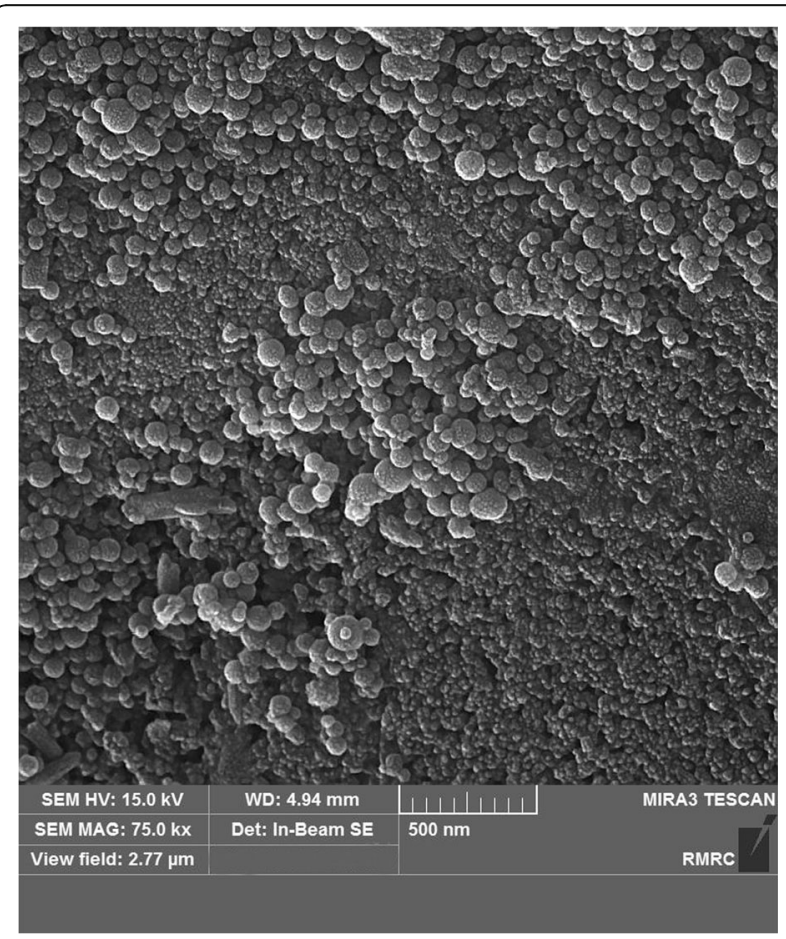

Fig. 10 FESEM image from group 3 showing fewer nanoparticles and less particle clustering 


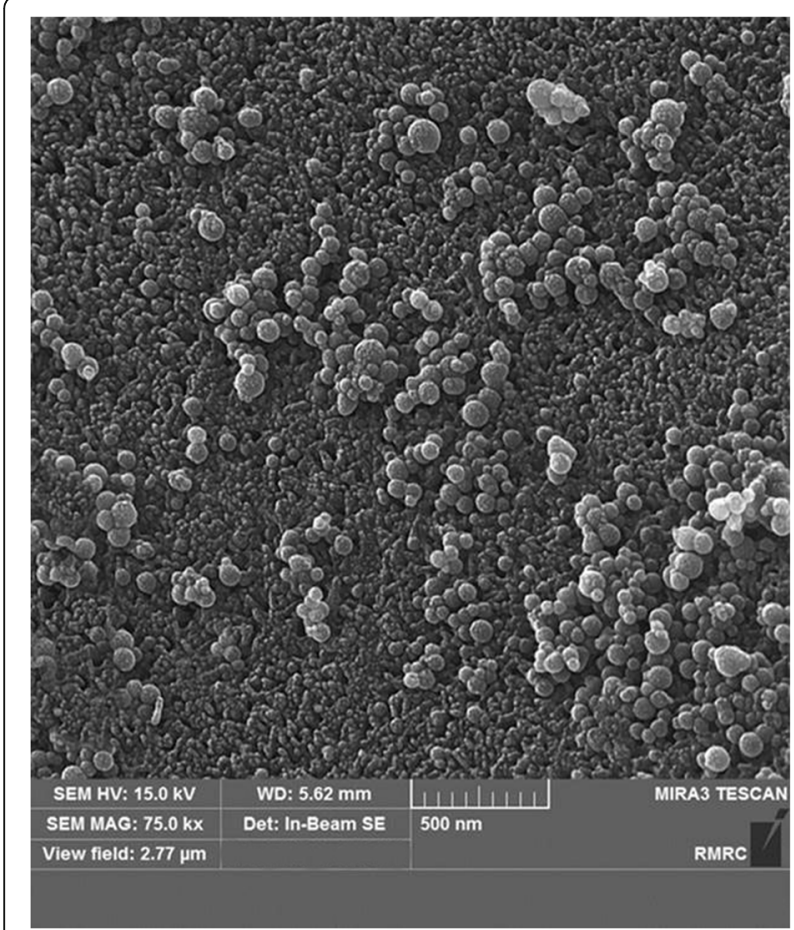

Fig. 11 FESEM image from group 4 showing spherical nanoparticles dispersed on the enamel

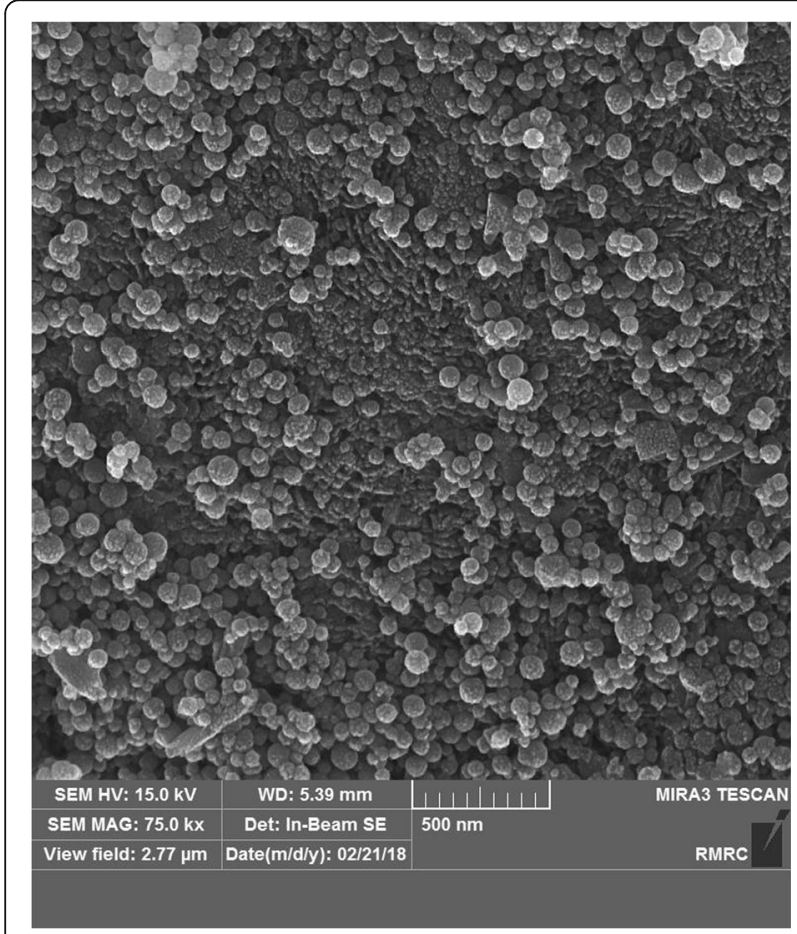

Fig. 12 FESEM image from group 5 showing nano-HA dispersal without cluster formation higher concentration of nano-HA), FESEM also showed larger amounts of nanoparticles dispersed on the surface area. In groups 4 and 5 (with SHMP), FESEM images showed more nanoparticles which were well dispersed on a larger surface area compared to groups 2 and 3. Earlier studies found that nonagglomerated particles are better able to penetrate into the surface and prevent nanoparticle precipitation [17, 25]. However, nanoparticle penetration into the deeper parts of the tooth was insufficient, as also reported by others [15].

A potential limitation of this study was that laboratory tests may not accurately reflect clinical conditions. To reduce the influence of confounding factors, we used thermocycling, which replicates actual clinical procedures. Another limitation is the lack of studies designed to investigate the effects of nanoparticles used prior to sealant application; this precluded comparisons between our findings and those of other studies. A further potential limitation is the approach we used to prepare the materials tested in each group. Therefore a pilot analysis was done to determine the appropriate concentrations of nano-HA and SHMP for testing before the experimental specimens were used for data collection and analysis. Our pilot study was based essentially on the methods of Besinis et al., and we implemented their 3:1 ratio of nano-HA to SHMP [24, 25]. However, we tested different concentration of nano-HA to obtain more complete results. The results of the present study support our hypothesis that nano-HA would be able to remineralize enamel and would enhance SBS without influencing the sealant's sealing ability. Finally, we recommend additional in vitro and in vivo studies to determine the advantages and drawbacks of applying nano-HA before the fissure sealant in terms of clinical outcomes.

\section{Conclusions}

The use of nano-HA before fissure sealant application may be an effective method to fill porous spaces in demineralized enamel pits and fissures, and to enhance remineralization compared to demineralized enamel. Moreover, the higher concentration of nano-HA (0.15\%) led to increased shear bond strength of the sealant compared to conventional acid etching and sealant application. Both concentrations of nano-HA (0.15 and 0.03\%) with or without SMHP led to enhanced remineralization compared to demineralized enamel.

\footnotetext{
Abbreviations

Ca: Calcium; CPP-ACP: Casein phosphopeptide-amorphous calcium phosphate; EDS: Energy-dispersive X-ray spectroscopy; FESEM: Field emission scanning electron microscope; FS: Pit and fissure sealant; NanoHA: Nanohydroxyapatite; P: Phosphate; SBS: Shear bond strength; SCi: Silicon carbide paper; SEM: Scanning electron microscopy; SHMP: Sodium hexametaphosphate
} 


\section{Acknowledgments}

The authors thank the Vice-Chancellery of Shiraz University of Medical Sciences for supporting the research. The authors thank Dr. M. Vossoughi of the Center for Improvement, Shiraz Dental School, for the statistical analysis, and K. Shashok (AuthorAID in the Eastern Mediterranean) for help with the English in the article. This article reports research done in partial fulfillment of the requirements for the PhD degree awarded to one of the authors, Dr. Mina Soltani.

\section{Funding}

Funding for this study was provided by the Vice-Chancellery of Shiraz University of Medical Sciences for the design of the study (Grant no. 96-15524).

\section{Availability of data and materials}

The datasets generated during and/or analyzed during the current study are available from the corresponding author on reasonable request.

\section{Authors' contributions}

MM, FS and AR. Conceptualization and design of the study, interpretation of data, drafting the manuscript, and approved the final manuscript as submitted. MS. Contributions to conceptualization and design the study, data collection, carried out the initial analyses, reviewed the manuscript, and approved the final manuscript as submitted. MHD. Conceptualized and designed the study, data acquisition and analysis, revising the manuscript critically for important intellectual content and approved the final manuscript as submitted. All authors approved the final manuscript as submitted and agree to be accountable for all aspects of the work.

\section{Ethics approval and consent to participate}

The research protocol was approved by the Human Ethics Review Committee of the School of Dentistry, Shiraz University of Medical Sciences (n\# IR.SUMS.REC.1396.S836). Written informed consent was obtained from all participants.

\section{Consent for publication}

Not applicable.

\section{Competing interests}

The authors declare that they have no competing interests.

\section{Publisher's Note}

Springer Nature remains neutral with regard to jurisdictional claims in published maps and institutional affiliations.

\section{Author details}

'Oral and Dental Disease Research Center, Department of Pediatric Dentistry, School of Dentistry, Shiraz University of Medical Sciences, Shiraz, Iran. ${ }^{2}$ Oral and Dental Disease Research Center, Department of Operative Dentistry, School of Dentistry, Shiraz University of Medical Sciences, Shiraz, Iran. ${ }^{3}$ Department of Restorative Sciences and Biomaterials, Henry M. Goldman School of Dental Medicine, Boston University, Boston, MA, USA.

\section{Received: 14 November 2018 Accepted: 9 May 2019}

\section{Published online: 28 May 2019}

\section{References}

1. SO G, Oong E, Kohn W, Vidakovic B, Gooch BF. CDC dental sealant systematic review work group, et al. the effectiveness of sealants in managing caries lesions. J Dent Res. 2008:87(2):169-74.

2. Use of Pit-and-Fissure Sealants. Pediatr Dent. 2017;39(6):156-72.

3. Deery C. Clinical practice guidelines proposed the use of pit and fissure sealants to prevent and arrest Noncavitated carious lesions. J Evid Based Dent pract. 2017;17(1):48-50.

4. Polk DE, Weyant RJ, Shah NH, Fellows JL, Pihlstrom DJ, Frantsve-Hawley J. Barriers to sealant guideline implementation within a multi-site managed care dental practice. BMC oral health. 2018;18(1):17.

5. Fontana M, Platt JA, Eckert GJ, Gonzalez-Cabezas C, Yoder K, Zero DT, et al. Monitoring of sound and carious surfaces under sealants over 44 months. J Dent Res. 2014;93(11):1070-5.

6. Fumes $A C$, Longo DL, De Rossi A, Fidalgo T, de Paula ESFWG, Borsatto MC, et al. Microleakage of sealants after phosphoric acid, Er: YAG laser and air abrasion enamel conditioning: systematic review and meta-analysis. J Clin Pediatr Dent. 2017:41(3):167-72.

7. Chiang ML, Birlbauer S, Lo YF, Pitchika V, Crispin A, llie N, et al. Which factors influence the shear bond strength of sealant materials? J Adhes Dent. 2016;18(5):397-404.

8. Kielbassa AM, Ulrich I, Schmid R, Schüller C, Frank W, Werth VD. Resin infiltration of deproteinised natural occlusal subsurface lesions improves initial quality of fissure sealing. Int J Oral Sci. 2017;9(2):117-24.

9. Borges BC, Campos GB, da Silveira AD, de Lima KC, Pinheiro IV. Efficacy of a pit and fissure sealant in arresting dentin non-cavitated caries: a 1-year follow-up, randomized, single-blind, controlled clinical trial. Am J Dent 2010; 23(6):311-316

10. Muller-Bolla M, Courson F, Lupi-Pegurier L, Tardieu C, Mohit S, Staccini P, et al. Effectiveness of resin-based sealants with and without fluoride placed in a high caries risk population: multicentric 2-year randomized clinical trial. Caries Res. 2018;52(4):312-22.

11. Delben AC, Cannon M, Vieira AE, Basso MD, Danelon M, Santo MR, et al. Analysis of anticaries potential of pit and fissures sealants containing amorphous calcium phosphate using synchrotron microtomography. Oper Dent. 2015;40(2):218-23.

12. Borges BC, Catelan A, Sasaki RT, Ambrosano GM, Reis AF, Aguiar FH. Effect of the application of a casein phosphopeptide-amorphous calcium phosphate (CPP-ACP) paste and adhesive systems on bond durability of a fissure sealant. Odontology. 2013;101(1):52-9.

13. Burbank BD, Cooper RL, Kava A, Hartjes JM, McHale WA, Latta MA, et al. Ion release and in vitro enamel fluoride uptake associated with pit and fissure sealants containing microencapsulated remineralizing agents. Am J Dent. 2017;30(2):59-64

14. Shinonaga Y, Arita K, Nishimura T, Chiu SY, Chiu HH, Abe Y, et al. Effects of porous-hydroxyapatite incorporated into glass-ionomer sealants. Dent Mater J. 2015;34(2):196-202.

15. Tavassoli-Hojjati S, Atai M, Haghgoo R, Rahimian-Imam S, Kameli S, Ahmaian-Babaki F, et al. Comparison of various concentrations of tricalcium phosphate nanoparticles on mechanical properties and remineralization of fissure sealants. J Dent (Tehran, Iran). 2014;11(4):379-88.

16. Salas-Lopez EK, Pierdant-Perez M, Hernandez-Sierra JF, Ruiz F, Mandeville $P$, Pozos-Guillen AJ. Effect of silver nanoparticle-added pit and fissure sealant in the prevention of dental caries in children. J Clin Pediatr Dent. 2017:41(1):48-52.

17. Cheng L, Zhang K, Weir MD, Melo MA, Zhou X, Xu HH. Nanotechnology strategies for antibacterial and remineralizing composites and adhesives to tackle dental caries. Nanomedicine (London, England). 2015;10(4):627-41.

18. Hannig M, Hannig C. Nanotechnology and its role in caries therapy. Adv Dent Res. 2012;24(2):53-7.

19. Nozari A, Ajami S, Rafiei A, Niazi E. Impact of Nano hydroxyapatite, Nano silver fluoride and sodium fluoride varnish on primary teeth enamel remineralization: an in vitro study. J Clin Diagn Res. 2017;11(9):Zc97-zc100.

20. Pepla E, Besharat LK, Palaia G, Tenore G, Migliau G. Nano-hydroxyapatite and its applications in preventive, restorative and regenerative dentistry: a review of literature. Ann Stomatol. 2014:5(3):108-14.

21. Vandiver J, Dean D, Patel N, Bonfield W, Ortiz C. Nanoscale variation in surface charge of synthetic hydroxyapatite detected by chemically and spatially specific high-resolution force spectroscopy. Biomaterials. 2005;26: 271-83.

22. Lee JJ, Lee YK, Choi BJ, Lee JH, Choi HJ, Son HK, et al. Physical properties of resin-reinforced glass ionomer cement modified with micro and nanohydroxyapatite. J Nanosci Nanotechnol. 2010;10(8):5270-6.

23. Tschoppe P, Zandim DL, Martus P, Kielbassa AM. Enamel and dentine remineralization by nano-hydroxyapatite toothpastes. J Dent. 2011 Jun;39(6):430-7.

24. Besinis A, van Noort R, Martin N. The use of acetone to enhance the infiltration of HA nanoparticles into a demineralized dentin collagen matrix. Dent Mater. 2016;32(3):385-93.

25. Besinis A, van Noort R, Martin N. Infiltration of demineralized dentin with silica and hydroxyapatite nanoparticles. Dent Mater. 2012;28(9):1012-23.

26. ten Cate JM, Duijsters PP. Alternating demineralization and remineralization of artificial enamel lesions. Caries Res. 1982;16(3):201-10.

27. Kucukyilmaz E, Savas S. Evaluation of shear bond strength, penetration ability, microleakage and remineralisation capacity of glass ionomer-based fissure sealants. Eur J Paediatr Dent. 2016:17(1):17-23.

28. Huang S, Gao S, Cheng L, Yu H. Remineralization potential of nanohydroxyapatite on initial enamel lesions: an in vitro study. Caries Res. 2011; 45(5):460-8 
29. Huang S, Gao S, Cheng L, Yu H. Combined effects of nano-hydroxyapatite and Galla chinensis on remineralisation of initial enamel lesion in vitro. J Dent. 2010;38(10):811-9.

30. Memarpour M, Shafiei F. Comparison of 3 one-bottle adhesives on fissure sealant microleakage: an in vitro study. J Dent Child. 2013;80(1):16-9.

31. Kakaboura A, Matthaiou L, Papagiannoulis L. In vitro study of penetration of flowable resin composite and compomer into occlusal fissures. Eur J Paediatr Dent. 2002;3(4):205-9.

32. Stavridakis MM, Favez V, Campos EA, Krejci I. Marginal integrity of pit and fissure sealantsQualitative and quantitative evaluation of the marginal adaptation before and after in vitro thermal and mechanical stressing. Oper Dent. 2003;28(4):403-14.

33. Feilzer AJ, De Gee AJ, Davidson CL. Relaxation of polymerization contraction shear stress by hygroscopic expansion. J Dent Res. 1990;69(1):36-9.

34. Featherstone JD. Dental caries: a dynamic disease process. Aust Dent J. 2008:53(3):286-91.

35. Guerra I, Cardell C. Optimizing use of the structural chemical analyser (variable pressure FESEM-EDX Raman spectroscopy) on micro-size complex historical paintings characterization. J Microsc. 2015;260(1):47-61.

Ready to submit your research? Choose BMC and benefit from:

- fast, convenient online submission

- thorough peer review by experienced researchers in your field

- rapid publication on acceptance

- support for research data, including large and complex data types

- gold Open Access which fosters wider collaboration and increased citations

- maximum visibility for your research: over $100 \mathrm{M}$ website views per year

At $\mathrm{BMC}$, research is always in progress.

Learn more biomedcentral.com/submissions 